\title{
UTILIZAÇÃO DE UM RECURSO EDUCACIONAL ABERTO NO CURSO DE BIOLOGIA DA EAD/UAB/UFT
}

\author{
PALMAS/TO JULHO/2018
}

\author{
Geny Batista Ferreira - SEDUC TO - gbatistaferreira@gmail.com \\ José Antônio Aguiar Gama - SEDUC To - josegama98@gmail.com \\ Rosita Félix Delmondes - SEDUC TO - rositalima@gmail.com \\ Fábio de Jesus Castro - UFT TO - fabiojesus2018@gmail.com \\ Telma Reijane Pinheiro da Costa - UFT - telmarpc@mail.uft.edu.br \\ Gentil Veloso Barbosa - UFT - gentil@mail.uft.edu.br
}

Tipo: Relato de Experiência Inovadora (EI)

Categoria: Pesquisa e Avaliação

Setor Educacional: EDUCAÇÃO SUPERIOR

\begin{abstract}
RESUMO
O artigo apresenta um relato de experiência sobre a utilização de um Recurso Educacional Aberto REA, da plataforma Khan Academy, realizada em três turmas do curso de graduação em biologia, na modalidade a distância e no ambiente Moodle da EaD/UAB/UFT. A partir do estudo realizado, percebeu-se a ausência da utilização de um recurso educacional aberto - REA no processo ensino $e$ aprendizagem na EAD. Assim, o objetivo deste estudo é Investigar se um Recurso Educacional Aberto - REA, poderá ser aceito como estratégia pedagógica pelos alunos em cursos de educação à distância - EAD. A pesquisa ocorreu em um encontro presencial nos pólos da Universidade Aberta do Brasil UAB nas cidades de Porto Nacional, Arraias e Gurupi e contou com a participação de 51,84\% dos alunos. Os dados foram coletados por meio de questionários elaborados de acordo com a skala likert $e$ validados com o índice de coeficiência RWG para análise da relevância das questões. Constatou-se por meio dos resultados que o recurso utilizado teve aceitação acima de $80 \%$, nos aspectos entendimento, contribuição e auxílio do REA à aprendizagem, demonstrando que o uso de outros recursos pedagógicos ao conteúdo programático do curso é uma estratégia necessária, principalmente na $E a D$.
\end{abstract}

Palavras-chave: Recursos Abertos. Repositórios Educacionais. Khan Academy. Educação a Distância.

Palavras-chave: Recursos Abertos. Repositórios Educacionais. Khan Academy. Educação a Distância.

\section{AGRADECIMENTOS}

AOS PROFESSORES, TUTORES E COORDENAÇÃo PEDAGÓGICA dO CURSO DE GRAUDAÇÃO EM BIOLOGIA DA EAD/UAB/UFT. 


\section{Introdução}

Nas últimas décadas, a democratização do acesso possibilitou um desenvolvimento expressivo na educação, viabilizando novas formas de ensinar e aprender por meio do acesso livre, colaboração e do compartilhamento de conteúdos abertos disponíveis na Internet, como os recursos didáticos de apoio ao ensino, tornando a educação a distância - EAD, uma opção recorrente, acessível e significativa.

É nesse contexto que os Recursos Educacionais Abertos - REA ganharam notoriedade após evento promovido pela UNESCO, em 2002 (Unesco, 2014), tornando-se importantes aliados na preservação, acesso e compartilhamento de conteúdos que podem ser pesquisados, remixados e recuperados para uso posterior. É considerado um REA qualquer tipo de ferramenta, material ou técnica de ensino e pesquisa, suportado por mídias digitais ou não, desde que esteja sob domínio público, permitindo sua utilização ou adaptação por terceiros.

Os REA são conteúdos de aprendizado, ferramentas tecnológicas e recursos para implementação e contribuem para uma transformação fundamental na educação: a promoção da autoria. As políticas públicas governamentais tem incentivado a utilização, criação e implementação dos REA por meio de congressos e conferências educacionais, importantes aliadas na divulgação e suporte à disseminação e uso dos REA.

Assim, a proposição deste estudo é: qual a percepção dos alunos em relação à implementação de um recurso educacional aberto - REA no processo ensino e aprendizagem na EAD/UaB/UFT e no ambiente Moodle? A hipótese que poderá sustentar ou descartar esse questionamento retoma o início desta pesquisa, quando buscou-se entender se o uso de um REA como recurso complementar ao conteúdo curricular do curso, proporciona aos alunos alternativas para compreender o conteúdo estudado em seu tempo e ritmo. Considerou-se, ainda, a relevância do ambiente Moodle dentro do processo formativo da EaD/UAB/UFT e a maneira pela qual um estudante ou professor pode se integrar por meio de uma proposta diferenciada na aquisição de conhecimentos.

Tendo em vista suas características como um software livre de desenvolvimento colaborativo, optou-se pela plataforma Moodle considerando seu aprimoramento contínuo e de código aberto, que permite a criação de sites de forma dinâmica para comunidades de aprendizagem, como pesquisadores, professores e alunos. O Moodle é utilizado para produção e gerenciamento de atividades educacionais, auxilia os educadores a compartilharem conteúdos e gerenciar suas atividades online. É um 
sistema modular baseado em plugins, que são como peças para construir atividades baseadas no princípio da interação e compartilhamento. Desde 2001, o software pode ser utilizado e até mesmo distribuído na linguagem Personal Home Page - PHP, disponível em diversos idiomas.

Conciliando estas especificidades, objetivou-se Identificar se um Recurso Educacional Aberto - REA, poderá ser uma estratégia pedagógica em cursos de educação a distancia - EAD e no Moodle. Os dados foram coletados por meio de questionários elaborados de acordo com a skala likert e validados com o índice de coeficiência RWG para análise da relevância das questões. Dessa forma, foi utilizado um REA da plataforma Khan Academy, cujo diferencial consiste na disponicilziação de aulas gratuitas em vídeos (REAs) ofertados de forma aberta. Considerou-se também, a organização dos conteúdos no site, com vídeos de curta duração introduzindo cada conteúdo específico com o auxílio de outros recursos (tirinhas, desenhos, gráficos, animações). Ao final do estudo, é disponibilizado um exercício e à medida que o aluno acerta e avança, é premiado virtualmente pelo progresso alcançado.

Contribuem com este estudo os autores Khan (2013), Silva (2010), Santan, Rossini e Pretto (2012), no sentido de demostrar como a tecnologia, disponibilizada através dos REA, pode favorecer novas aprendizagens. $O$ artigo segue a seguinte organização: na seção 1 apresenta-se o contexto da pesquisa por meio do Referencial Teórico; na seção 2 aborda-se a metodologia; na seção 3 apresenta-se a análise dos resultados da pesquisa e seus desdobramentos e, finalmente, na seção 4 faz-se as considerações finais com sugestões para pesquisas futuras.

\section{Referencial Teórico}

Nesta pesquisa, pretende-se apresentar à luz da literatura, o conceito de REA, evolução e utilização no contexto das tecnologias aplicadas à educação. De acordo com Santana, Rossini e Pretto (2012, p. 27):

\footnotetext{
podemos verificar que práticas abertas implicam em uma ideologia educacional. Direcionam para uma postura crítica diante do conhecimento, principalmente diante da expansão do conceito de autoria; reconhecem que $o$ recurso didático deve ser manipulável e adaptável aos contextos de aprendizado. [...] Essas e outras possibilidades estão ligadas aos ideais de uma educação para o século XXI, com escolas como "organizações de aprendizagem".
}

Em conformidade com a disseminação dos REA em escala global, a Declaração da Cidade do Cabo (Unesco, 2017, p. 15) considera que "esta metodologia de educação é construída sobre a crença de que todos devem ter a liberdade de usar, personalizar, 
melhorar e redistribuir os recursos educacionais, sem restrições. Educadores, estudantes e outras pessoas que partilham esta crença estão unindo-se em um esforço mundial para tornar a educação mais acessível e mais eficaz".

Disponibilizados em vários formatos que vão desde livros, planos de aula, softwares, jogos, vídeos, áudios e imagens, os REA podem ser utilizados, reutilizados ou recombinados com outros objetos, aumentando assim o acesso ao conhecimento. Neste contexto, a EaD constitui-se em ambiente promissor, considerando a relevância do uso dos REA, conforme Santana, Rossini e Pretto (2012, p. 27), apud (MOTA; FILHO, CASSIANO, 2006):

é aberto também porque a modalidade de educação a distância constitui importante estratégia para aumentar a oferta de educação superior nas regiões distantes dos grandes centros, diminuindo, portanto, as barreiras geográficas de acesso à educação.

O Brasil vivencia um momento importante de democratização do acesso à educação, mediante iniciativas como: Portal do professor, Domínio público, Rived, etc.. É neste contexto que a Khan Academy tornou-se referência em educação aberta e de qualidade, pautada na filosofia de aprendizagem gratuita. Com a missão de fornecer educação de qualidade para qualquer um, em qualquer lugar a Khan Academy é uma Organização não Governamental - ONG educacional, criada e sustentada por Samuel Khan.

Por meio de tecnologias adaptativas, a plataforma identifica os pontos fortes e lacunas no aprendizado dos alunos, disponibilizando um programa de acompanhamento e vídeos de instrução. Os estudantes recebem um painel de exercícios personalizados que habilita a preparação de acordo com o próprio ritmo de cada um, dentro e fora da sala de aula. No Brasil, desde 2014, a Fundação Lemann apostou no projeto de Khan e passou traduzir para o português as aulas que já foram vistas por milhões de pessoas no mundo.

Trazendo como princípio a inteligência artificial - IA - como recurso fundamental à motivação, os conteúdos disponibilizados visam o incentivo e o autoconhecimento. Khan (2013, p. 20) afirma:

\footnotetext{
gosto de pensar na Khan Academy com uma extensão virtual dessa noção de "um mundo, uma escola". É um lugar onde todos são bem-vindos, todos estão convidados a ensinar e a aprender, e todos são incentivados a fazer o melhor possível. O sucesso é autodefinido; o único fracasso é desistir.
}

Assim, os conteúdos disponíveis na plataforma Khan Academy incentivam a criação e a disseminação de REA, cuja finalidade envolve o compartilhamento de produções que 
podem ser utilizadas em diversos contextos, promovendo o conhecimento, a pesquisa e a cultura de uma educação que aproximam o aluno de um currículo vivo e dinâmico.

\section{2 - Metodologia}

A pesquisa compreendeu três etapas: (1) planejamento da realidade estudada; (2) Organização dos conteúdos e questionários e (3) tratamento e análise dos dados coletados. A metodologia utilizada foi a qualiquantitativa pois segundo Creswell (2010, p. 12), "o desenvolvimento e a legitimidade percebida de ambos os métodos [...], proporciona uma maior compreensão dos problemas estudados", visto que os métodos e técnicas são complementares na discussão dos resultados.

Participaram da pesquisa $51,84 \%$ dos alunos das três turmas do curso de Biologia nas cidades de Porto Nacional, Arraias e Gurupi em Março/2017, com 80 alunos. No período matutino, realizou-se a socialização dos conteúdos da plataforma Khan Academy relacionados ao eixo biológico III, bloco I, estudado no decorrer do semestre.

A coleta de dados foi realizada através da aplicação de um questionário organizado de acordo com a scala likert com pontuação de 1 a 5 , (sendo 1 para discordo totalmente e 5 concordo totalmente) e tabulados em planilha eletrônica (Excel). A utilização da skala likert considerou sua especificidade em avaliar a concordância de uma afirmação por meio de diferentes níveis de medição que podem variar de 5 a 9 alternativas, tendo um elemento neutro para aqueles que não concordam e nem discordam. Segundo Costa (2011, p. 12), permite ainda, conhecero grau de conformidade do entrevistado com qualquer afirmação proposta, em que a frequência estatística determina qual é a importância atribuída ao produto investigado e a probabilidade de sucesso na realização de ações futuras.

Os dados foram analisados com base no coeficiente de concordância RWG, considerando a média das pontuações das questões e o grau de concordância entre as mesmas. Como mapeamento, elaborou-se um questionário demográfico, (pólo e formação). Após apresentação do tema da pesquisa e socialização do conteúdo na plataforma Khan Academy, foi aplicado um questionário com 10 perguntas sobre o REA utilizado. As respostas podem ser melhor compreendidas na apresentação dos resultados.

\section{Apresentação e Discussão dos resultados}

A pesquisa foi aplicada em um encontro presencial ao final do semestre, quando 
explicou-se aos alunos sua finalidade, objetivos e possíveis contribuições ao meio acadêmico, com a garantia do anonimato aos participantes. O gráfico 1 apresenta os dados demográficos relacionados à formação acadêmica dos participantes da pesquisa nas cidades-sede envolvidas neste estudo.

Gráfico 01 - Formação Acadêmica.

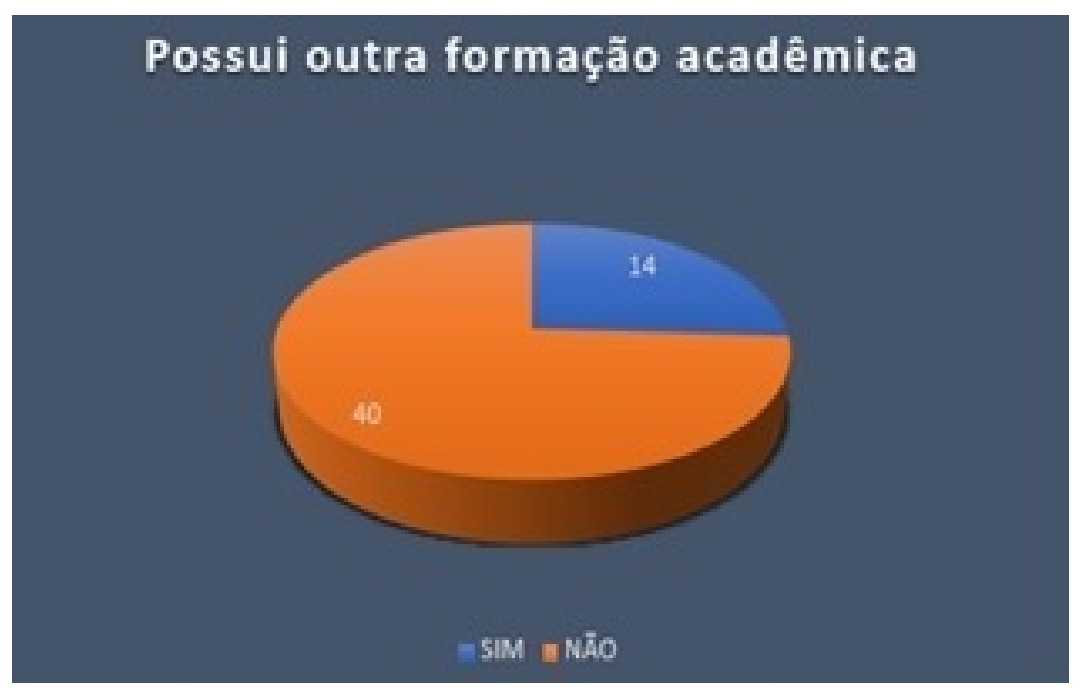

Com um público alvo heterogêneo, observou-se que parte significativa dos respondentes são egressos do ensino médio, profissionais da saúde de área técnica e professores sem formação adequada na rede pública de ensino. Os respondentes que informaram ter outra formação, apesar de serem em menor número, demonstraram dedicação e interesse em participar da pesquisa. A seguir, o gráfico 2 apresenta a análise e 0 percentual comparativo das percepções dos alunos em relação aos conteúdos estudados.

Gráfico 02 - Contribuição e Entendimento do Conteúdo - REA

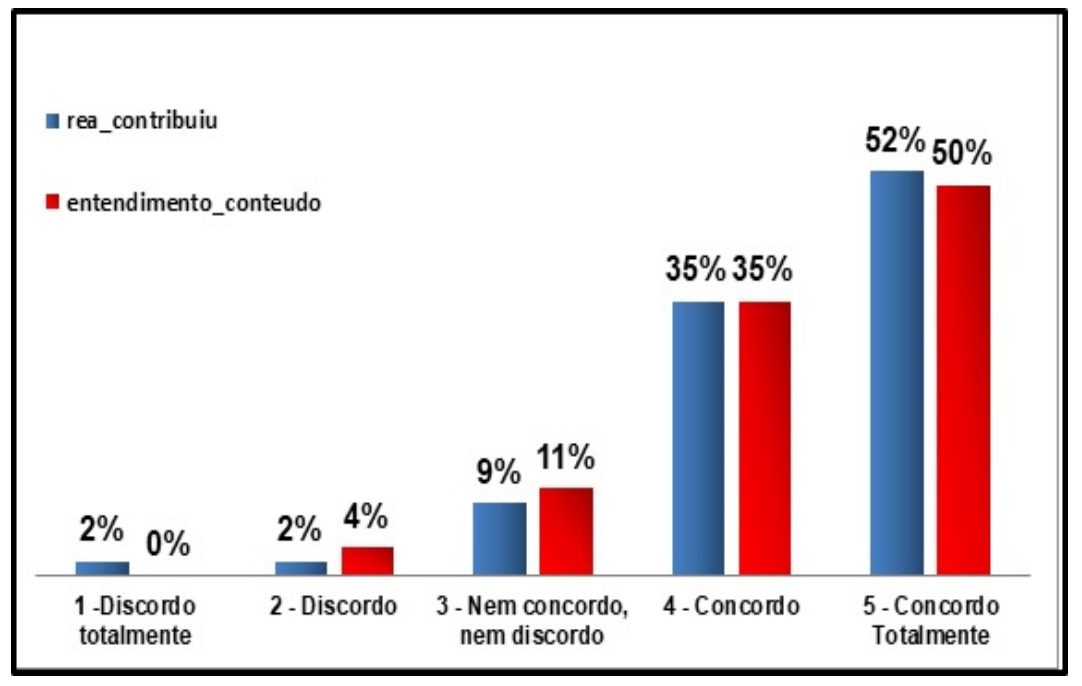


Ao serem questionados se "oconteúdo da disciplina estudada, com o auxílio do Recurso Educacional, contribuiu para sua aprendizagem" e "o Recurso Educacional disponibilizado favoreceu o seu entendimento em relação ao conteúdo do eixo estudado?", a concordância acima de $85 \%$, nos índices 4 e 5 (concordo e concordo totalmente) fortaleceram a concepção de que a maioria dos alunos compreenderam que o REA utilizado, atendeu suas necessidades de aprendizagem.

Gráfico 03 - Conteúdo Khan Academy e Qualidade Informações

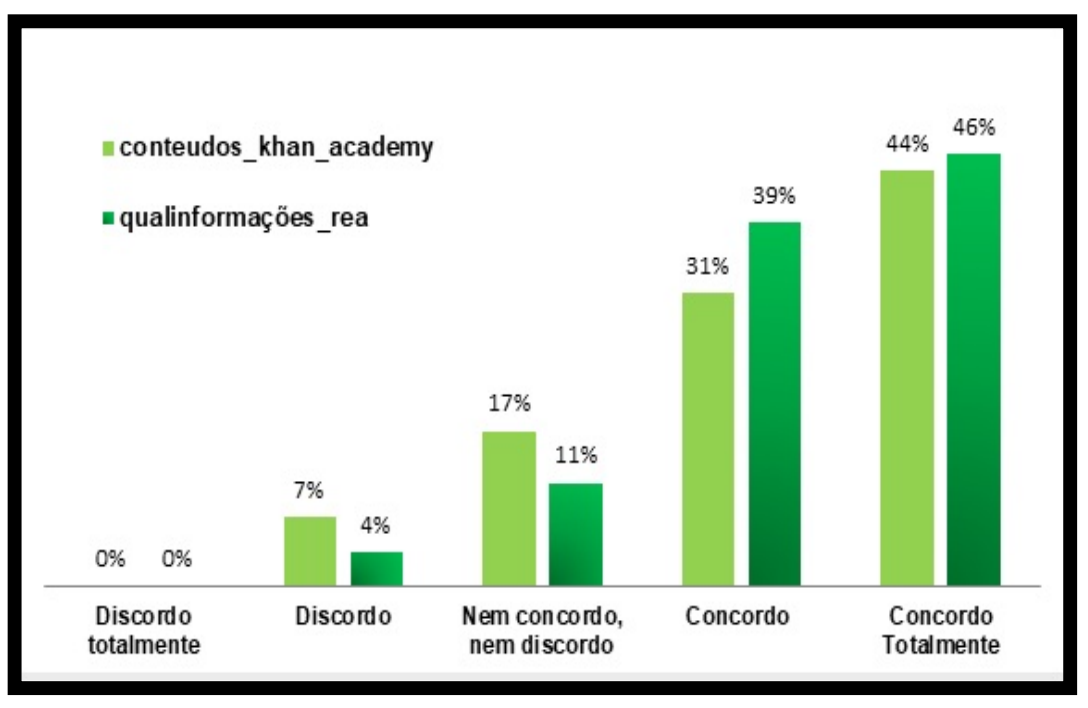

O gráfico 03 apresenta as respostas relacionadas às perguntas "os conteúdos apresentados no REA na Khan Academy foram abordados de forma clara e precisa? e "a qualidade das informações do REA no ambiente do curso foram relevantes para o seu conhecimento?". As respostas obtiveram percentuais acima de $75 \%$ nos índices 4 e 5 , indicando uma aceitação positiva quanto ao REA utiizado, deixando evidente também, que a maior parte dos alunos consideram que os conteúdos curriculares disponíveis no eixo estudado podem ser melhor compreendidos com o auxílio de um recurso educacional.

Gráfico 04 -Adequação e acompanhamento - REA 


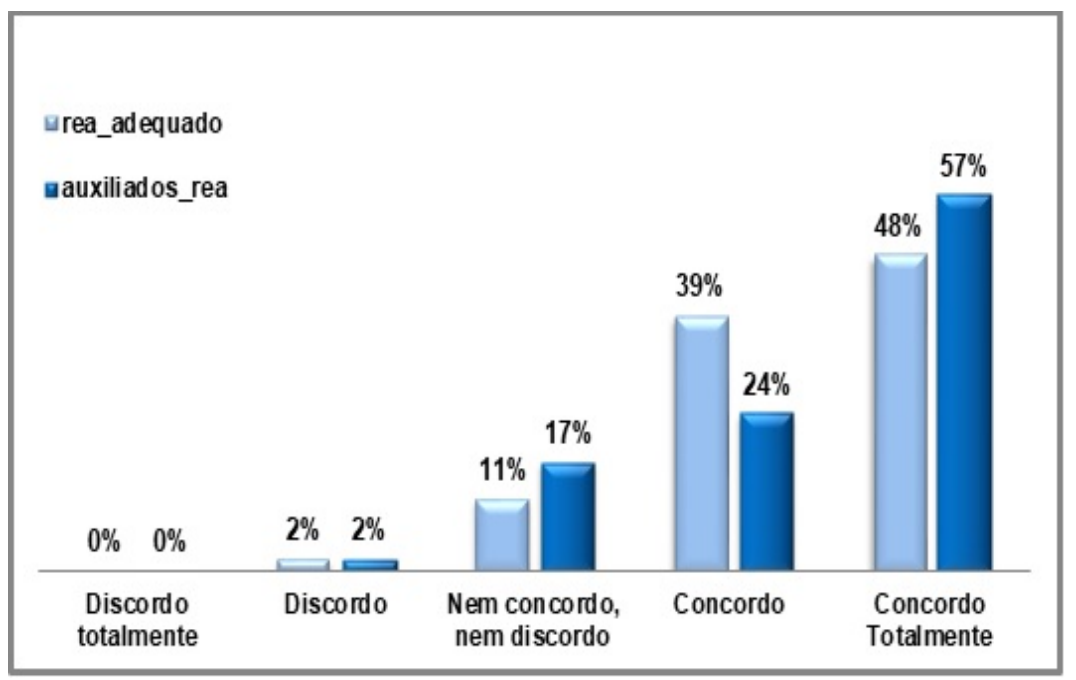

Em resposta à pergunta se "o Recurso Educacional utilizado se mostrou adequado ao conteúdo que você está estudando" e se "em sua opinião, os conteúdos devem ser auxiliados de um REA?", a aceitação acima de $80 \%$ às perguntas, indicou a relevância do recurso utilizado, o que retoma ao conceito principal difundido por Khan (2013), cuja filosofia é: "aprendizagem gratuita e de qualidade, a qualquer hora e a qualquer lugar". Esses percentuais sinalizam que há expectativas dos alunos em relação ao acesso a materiais educativos no ambiente do curso que contemplem suas necessidades de aprendizagem.

Gráfico 05 - Necessidade de aprendizagem e conteúdos acompanhados por um REA.

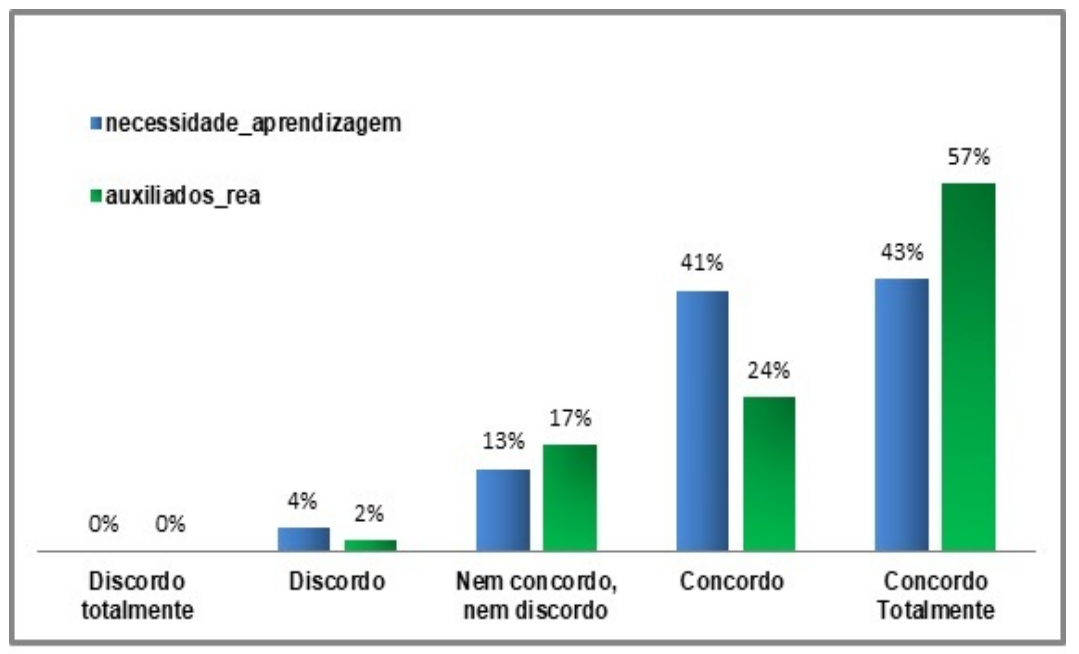

Quanto à pergunta "O Recurso Educacional utilizado atendeu à sua necessidade de aprendizagem?" e "na sua opinião, os conteúdos devem ser auxiliados de um REA?" com uma concordância acima de $81 \%$ nos dois questionamentos, um número significativo de alunos concordaram que os conteúdos estudados com o auxilio de um REA atenderam suas necessidades de aprendizagem e devem ser acompanhados de 
um recurso educacional, validando assim o objetivo deste estudo.

\section{Considerações finais}

A utilização de um REA no curso de graduação em Biologia e a análise comparativa dos percentuais obtidos em cada resposta relacionada ao uso do recurso como estratégia complementar ao conteúdo estudado no semestre, evidenciou que é fundamental a adoção de práticas pedagógicas alternativas como instrumento para a disseminação, compartilhamento e universalização do conhecimento. Durante as etapas de planejamento da pesquisa, observou-se que o REA não era conhecido por alguns professores colaboradores, porém no decorrer do processo de apropriação do REA da Khan Academy, estes sentiram-se motivados com a possibilidade de aprender algo novo e melhorar suas práticas.

Quanto aos alunos, constatou-se por meio da análise das respostas, que estes consideram necessário aprimorar a forma como o conteúdo é disponibilizado na plataforma do curso. A análise das percepções relacionadas ao uso do REA trouxe à tona uma realidade perceptível: os alunos necessitam de acesso à conteúdos educacionais que contemplem suas expectativas de aprendizagem. Desse modo, os conteúdos da Khan Academy podem contribuir como recurso de expressiva significação devido sua configuração planejada para motivar o aluno a aprender de forma autônoma, em seu tempo e rítmo.

A análise comparativa por meio do índice de coeficiência RWG, validou as percepções dos alunos, confirmando um nível de satisfação acima da média, com destaque para a pergunta "em sua opinião, os conteúdos devem ser auxiliados de um REA", obteve a maior pontuação, sinalizando para uma relevância que deve ser considerada como ponto de partida para estudos futuros. As resposta às perguntas "contribuição do REA" e "entendimento do conteúdo com o auxílio de um REA" também evidenciaram que os alunos em sua maioria, consideraram que foram contemplados nestes aspectos, sinalizando para a necessidade da equipe pedagógica do curso, refletir sobre a forma como o conteúdo curricular é disponibilizado.

Indica-se em pesquisas futuras, que a equipe pedagógica do curso de Biologia da $\mathrm{DTE} / \mathrm{UaB} / \mathrm{UFT}$, busque alternativas para efetivar novas práticas metodológicas a partir da utilização de um REA, considerando que o estudo realizado detectou este aspecto como ponto merecedor de implementações futuras. 


\section{Referências}

CONFERÊNCIA NACIONAL DE EDUCAÇÃO (CONAE), 2014-2024. O PNE na articulação do Sistema Nacional de Educação. Disponível em . Acesso em: 14 de Abril de 2018.Declaração REA de Paris 2012. Congresso mundial sobre recursos educacionais abertos. Unesco, Paris, 20 a 22 de junho de 2012.

COSTA. F. J. Mensuração e desenvolvimento de escalas: aplicações em administração. Rio de Janeiro: Ciência Moderna, 2011.

CRESWELL, J. W. Projeto de pesquisa: métodos qualitativo, quantitativo e misto. 3. ed. Porto Alegre: Artmed, 2010.

KHAN, Salman. Um mundo, uma escola. A Educação reinventada. Le Livros. Biblioteca do exilado. Tradução: George Schiesinger. Edição Digital, 2013.

MEC. Ministério da Educação. Conferência Nacional de Educação. Documento Final 2010. http://conae.mec.gov.br Acesso em: 05 jan. 2018.

SANTANA, Bianca. ROSSINI, Carolina. PRETTO, Nelson de Luca. Recursos Educacionais Abertos. Práticas colaborativas e políticas públicas. São Paulo/Salvador, 2012.

UNESCO. REA. Recursos Educacionais Abertos. Representação da Unesco no Brasil. Revista eletrônica. Unesco, 2017. 